\title{
PENYULUHAN OLAHRAGA DAN AKTIVITAS FISIK DALAM PENGATURAN TEKANAN DARAH PADA PANDEMI COVID-19
}

\author{
Susy Olivia Lontoh ${ }^{1}$, Alvin Nur Zahra ${ }^{2}$, Gracelya Esther Liwanto ${ }^{3}$ \\ ${ }^{1}$ Bagian Fisiologi , Fakultas Kedokteran, Universitas Tarumanagara Jakarta \\ Email: susyo@fk.untar.ac.id \\ ${ }^{2}$ Mahasiswa Fakultas Kedokteran Universitas Tarumanagara Jakarta \\ Email: Alfin2804@gmail.com \\ ${ }^{3}$ Mahasiswa Fakultas Kedokteran Universitas Tarumanagara Jakarta \\ Email: graceliwantoo@gmail.com
}

\begin{abstract}
Inactivity due to social restrictions leads to relaxed daily habits. Interventions in regulating a person's blood pressure can be through good activity and regular exercise. It is necessary to make recommended efforts to improve and maintain physical exercise habits at home and exercise regularly and correctly so that blood pressure can be controlled. Health education activities are carried out online for FK UNTAR partners, namely Tomang Village cadres on Saturday 2 October 2021 at 10.00-11.00 with the material "Managing Blood Pressure Through Physical Activity". Online education activities were carried out online and attended by 38 participants. The material conveyed the importance of exercise and physical activity even though the activity took place at home, recommended sports for people with high blood pressure and sports activities that can be done at home or homeexercise techniques. The implementation of the "Manage Blood Pressure Through Physical Activity" went smoothly and participants participated in a series of events to completion. The participants' lack of knowledge regarding physical activity and sports can be seen based on the average score of 11.40 and after the delivery of the material there is an increase in knowledge, it can be seen that the post-test results are 41.23. This activity can be carried out again as a follow-up of the results of this service activity and in collaboration with foster citizens to be diligent in exercising
\end{abstract}

Keywords: Physical activity, exercise, blood pressure control

\begin{abstract}
ABSTRAK
Inaktivitas akibat pembatasan sosial menimbulkan kebiasaan sehari-hari yang santai. Intervensi dalam pengaturan tekanan darah seseorang dapat melalui aktivitas baik dan olahraga teratur. Perlu dilakukan usaha yang direkomendasi untuk meningkatkan serta mempertahankan kebiasaan latihan fisik di rumah serta berolahraga secarta teratur dan benar agar tekanan darah dapat dikendalikan. Kegiatan edukasi kesehatan dilakukan sistem daring pada mitra FK UNTAR yaitu kader Kelurahan Tomang pada hari Sabtu 2 Oktober 2021 pukul 10.00-11.00 dengan materi "Kelola Tekanan Darah Melalui Aktivitas Fisik". Kegiatan edukasi online di lakukan secara dengan daring di hadiri 38 peserta. Materi yang disampaikan pentingnya olahraga serta aktivitas fisik walaupun kegiatan berlangsung dirumah, olahraga yang dianjurkan pada penderita darah tinggi serta kegiatan olahraga yang dapat dilakukan dirumah atau teknik home-exercise. Pelaksanaan kegiatan pengabdian "Kelola Tekanan Darah Melalui Aktivitas Fisik" berjalan dengan lancar dan peserta mengikuti rangkaian acara hingga selesai. Masih minimnya pengetahuan peserta terkait aktivitas fisik dan olahraga dapat dilihat berdasarkan nilai rata-rata pre test adalah 11,40 dan setelah penyampaian materi terjadi peningkatan pengetahuan dapat dilihat hasil pos test sebesar 41,23. Kegiatan ini dapat dilakukan kembali sebagai follow up dari hasil kegiatan pengabdian ini serta bekerjasama dengan kader untuk membina warganya untuk rajin berolahraga.
\end{abstract}

Kata kunci: Aktivitas fisik, olah raga, pengendalian tekanan darah

\section{PENDAHULUAN}

WHO dan pemerintah seluruh negara dalam upaya mencegah penyebaran Covid-19 merekomendasikan untuk melakukan karantina atau pembatasan kegiatan sosial warganya. Isolasi dan pembatasan dilakukan dengan berdiam diri di rumah, bekerja di rumah, penutupan area publik seperti taman, mall, fitness center, dan tempat tempat wisata lainnya. Kondisi ini menyebabkan masyarakat "terkurung" di rumahnya masing-masing, sebagian besar kegiatan dilakukan di rumah dan memilih aktivitas rekreasi seperti belajar memasak, lebih banyak 
menggunakan gadget dan kegiatan-kegiatan lain yang kurang aktif. Inaktivitas akibat pembatasan sosial menimbulkan kebiasaan sehari yang santai sehingga berakibat menurunnya fungsi sistem tubuh terutama fungsi jantung pembuluh darah yang berhubungan dengan tekanan darah. Tekanan darah tidak terkontrol pada orang yang jarang berolahraga memicu hipertensi (Halabachi, 2020).

Pola hidup yang jarang bergerak serta malas olahraga merupakan faktor risiko keempat dari mortalitas secara global yaitu 5.5\% kematian di dunia. Inaktivitas fisik menjadi faktor risiko utama dari hipertensi, baik pada pria maupun wanita segala usia (WHO, 2009; Hongkong Department of Health, 2012). Intervensi dalam pengaturan tekanan darah seseorang dengan cara aktivitas fisik yang baik dan olahraga teratur merupakan cara pencegahan dan kontrol terhadap penyakit tidak menular yang efektif dan hemat biaya (Roux, 2008) Pengaruh positif latihan fisik terhadap kondisi kesehatan dipengaruhi endorphin. Intensitas aktivitas fisik sedang, olahraga yang rutin dilakukan memengaruhi sekresi hormon endorfin yang dilepas setelah melakukan suatu aktivitas fisik, sehingga menimbulkan rasa bahagia, mengurangi nyeri, meningkatkan imunitas tubuh, meningkatkan rasa optimis dalam menghadapi masalah kehidupan serta membantu pengendalian tekanan darah (Hammami, et al., 2020; Koch, S., 2020 AuberinLeheudre, M., 2020). Berdasarkan uraian diatas manfaat dari aktivitas fisik serta olahraga teratur memberikan dampak positif bagi kesehatan terutama terkait tekanan darah, tetapi masih banyak orang dewasa yang tidak melakukan aktif fisik, satu dari empat orang dewasa kurang melakukan aktivitas fisik dan 26,1\% penduduk Indonesia termasuk dalam kategori dengan aktivitas fisik kurang. Jakarta merupakan provinsi yang dengan proporsi penduduk yang kurang aktivitas fisik tertinggi yaitu 44,2\% penduduk yang kurang melakukan aktivitas fisik.(WHO, 2015)

Maka perlu dilakukan suatu usaha yang direkomendasi secara tepat untuk meningkatkan serta mempertahankan kebiasaan latihan fisik di rumah serta berolahraga secarta teratur dan benar. Berdasarkan permasalahan terkait pandemi, inaktivitas fisik serta tekanan darah tidak terkendali yang paling banyak di alami usia dewasa muda, maka sasaran pada kegiatan ini ditujukan pada dewasa muda karena pada masa pandemi aktivitas fisik mereka sebagian besar di rumah, mereka jarang berolahraga serta tingkat aktivitas nya tergolong santai serta prevalensi tekanan darah tinggi banyak terjadi di usia dewasa muda.

\section{METODE PELAKSANAAN PKM}

Pada kegiatan pengabdian terkait edukasi olahraga untuk warga kelurahan Tomang Jakarta Barat di awali dengan persiapan pelaksanaan yang meliputi rapat koordinasi untuk persiapan awal pelaksanaan kegiatan melalui Zoom, survei kepada salah satu warga Tomang menanyakan aktivitas sehari-hari dan kebiasaan olahraga selama pandemi. Tim pengusul membuat proposal berdasarkan permasalahan yang terjadi serta ditetapkan model pelaksanaan yang paling memungkinkan, karena masih dalam kondisi PPKM. Kegiatan edukasi kesehatan dilakukan sistem daring pada mitra FK UNTAR yaitu kader Kelurahan Tomang pada hari Sabtu 2 Oktober 2021 pukul 10.00-11.00 WIB dengan materi "Kelola Tekanan Darah Melalui Aktivitas Fisik". Kegiatan edukasi online di lakukan secara dengan daring menyampaikan materi pentingnya olahraga serta aktivitas fisik walaupun kegiatan berlangsung dirumah, olahraga yang dianjurkan pada penderita darah tinggi serta kegiatan olahraga yang dapat dilakukan dirumah atau teknik home-exercise.

Sebelum mengikuti kegiatan bakti kesehatan ini, peserta harus melakukan pendaftaran dengan menggunakan formulir elektronik yang telah disedikan oleh tim pengabdian. Tim pengabdian membagikan link formulir pendaftaran 1 minggu sebelum kegiatan serta ditentukan usia 25-60 tahun, jarang berolahraga, pernah atau terkonfirmasi tekanan darah tinggi serta ada riwayat darah tinggi dirumah. Tim pengabdian membuat kuisioner pre-test untuk menilai pengetahuan awal 
terkait olahraga, aktivitas fisik dan hubungannya dalam mengendalikan tekanan darah sebagai upaya pencegahan hipertensi. Panitia pengabdian membagikan post test serta umpan balik dari kegiatan penyuluhan. Pre-test dan post-test dilakukan melalui google form yang dikirimkan melalui chat room Zoom. Tujuan dilakukan pretest adalah untuk menilai wawasan peserta pengabdian terkait aktivitas fisik dan post-test adalah mengetahui gambaran capaian wawasan peserta setelah penyampaian materi terkait aktivitas fisik dalam pengendalian darah.

\section{HASIL DAN PEMBAHASAN}

Pelaksanaan kegiatan edukasi kesehatan dilakukan sesuai dengan tanggal yang telah ditentukan hari Sabtu 2 Oktober 2021 pukul 10.00-11.00 WIB. Tim pengabdian sudah mulai bergabung di platform zoom meeting pukul 9.15 WIB, hal ini dilakukan mencegah terjadinya gangguan jaringan serta tim pengabdian sudah mulai mengingatkan mitra FK UNTAR yaitu kader Kelurahan Tomang untuk mengikuti edukasi dengan materi "Kelola Tekanan Darah Melalui Aktivitas Fisik". Pukul 9.50 WIB peserta yang sudah terdaftar pada link pendaftaran. Jumlah peserta yang mengikuti acara edukasi pengabdian sebanyak 38 peserta. Kegiatan diawali dengan sambutan santai, tim pengabdian menyapa semua peserta dan menanyakan bagaimana kabarnya. Peserta menjawab baik dan sudah tidak sabar untuk bertemu secara daring. Sebelum dimulai penyampaian materi maka peserta diminta untuk mengisi pre-test yang dibagikan di kolom chat. Materi disampaikan oleh dr. Susy Olivia Lontoh, M.Biomed. Peserta ditanyakan apakah masih suka berolahraga, senam ringan atau aktivitas fisik saat PPKM. Sebagian besar peserta menjawab jarang berolahraga, senam juga yang biasa dilakukan juga dibatasi serta semua kegiatan dirumah. Aktivitas yang paling banyak dilakukan hanya jalan kaki tapi juga jarang dikerjakan. Penyampaian materi terkait olahraga terdiri atas pentingnya olahraga serta aktivitas yang dianjurkan pemerintah. Pada kegiatan edukasi ini dijelaskan apa maksudnya aktivitas fisik, jenis aktivitas fisik yang dapat dilakukan dirumah seperti menyapu atau membersihkan rumah, jalan kaki. Olah raga yang baik, benar, terukur dan teratur. Materi olahraga untuk penderita hipertensi juga dijelaskan yaitu jenis olahraga yang ringan seperti jalan kaki, olahraga aerobik serta tips dalam melaksanakan olahraga. Di akhir penyampaian materi tim pengabdian mengajak peserta mengikuti senam hipertensi. Peserta secara antusias mengikuti gerakan senam.

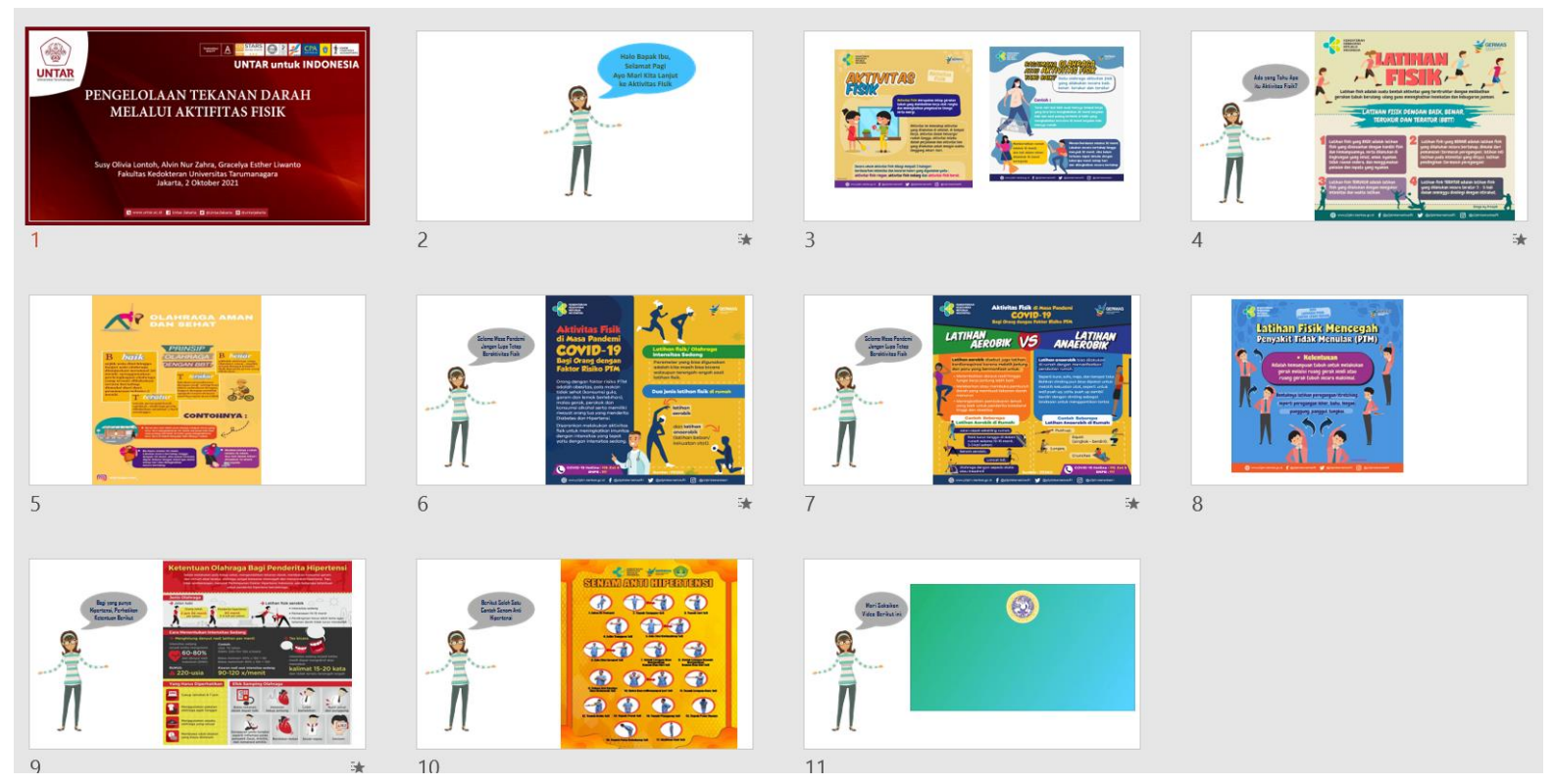

Gambar 1. Materi Penyuluhan 


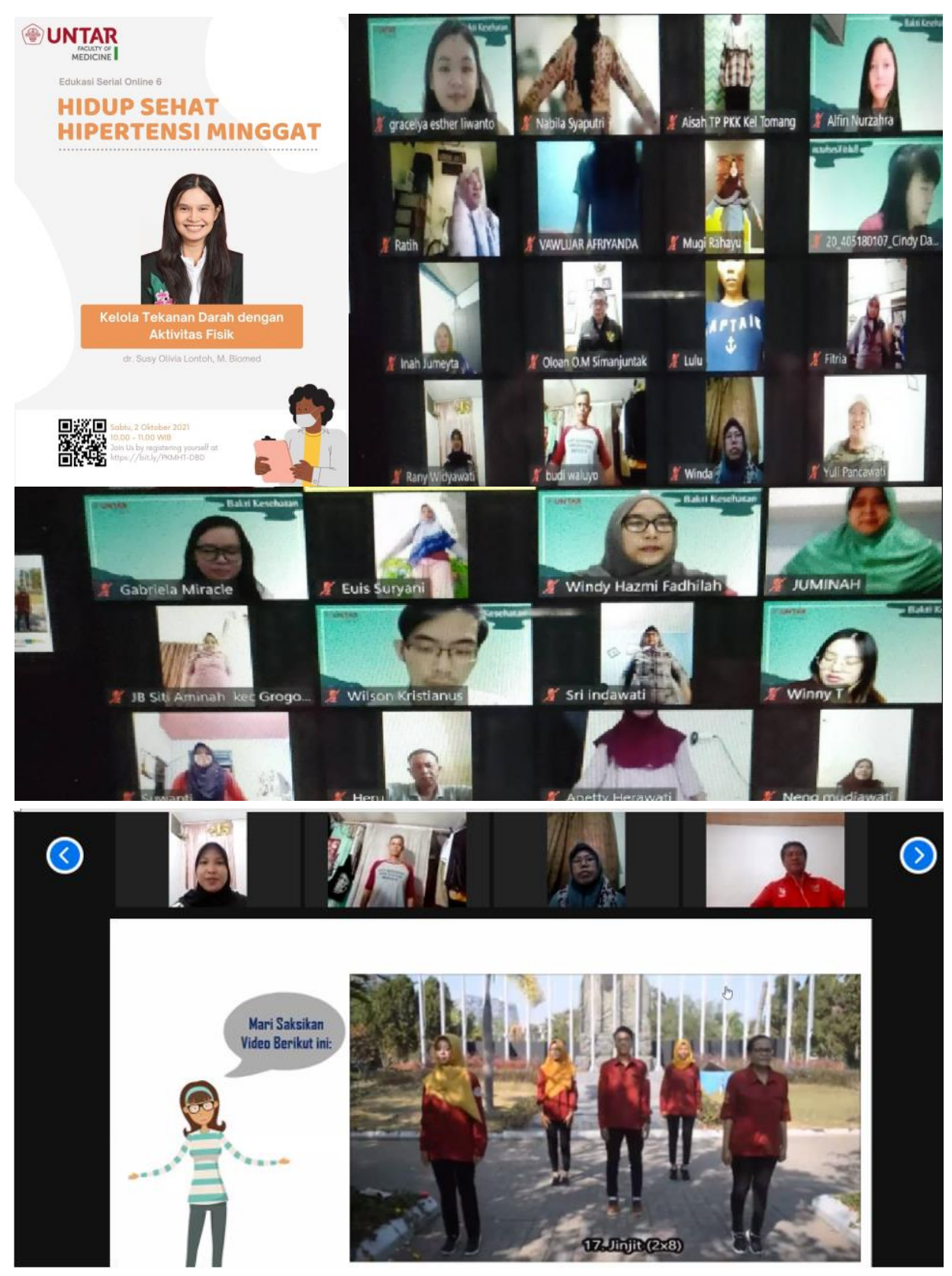

Gambar 2. Flyer dan Peserta PKM yang sedang senam

Sebelum kegiatan pengabdian berakhir peserta diminta mengisi soal pos tes yang telah disiapkan. Nilai rata-rata pre test adalah 11,40 dan nilai rata-rata pos test didapatkan hasil sebesar 41,23, dapat dilihat pada gambar 3. Berdasarkan hasil pre test dan pos test pada kegiatan edukasi ini dapat dilihat terjadinya peningkatan pengetahuan terkait materi olahraga dalam pengendalian olahraga. Hasil dari pretest dapat dilihat masih minimnya pengetahuan terkait aktivitas fisik, olahraga yang dianjurkan dan setelah penyampaian materi terjadi peningkatan pengetahuan para peserta. Target jangka pendek kegiatan ini adalah menambah kesadaran pada masyarakat pentingnya olahraga dan aktivitas fisik dalam kehidupan sehari-hari terutama pada masa pandemi. 


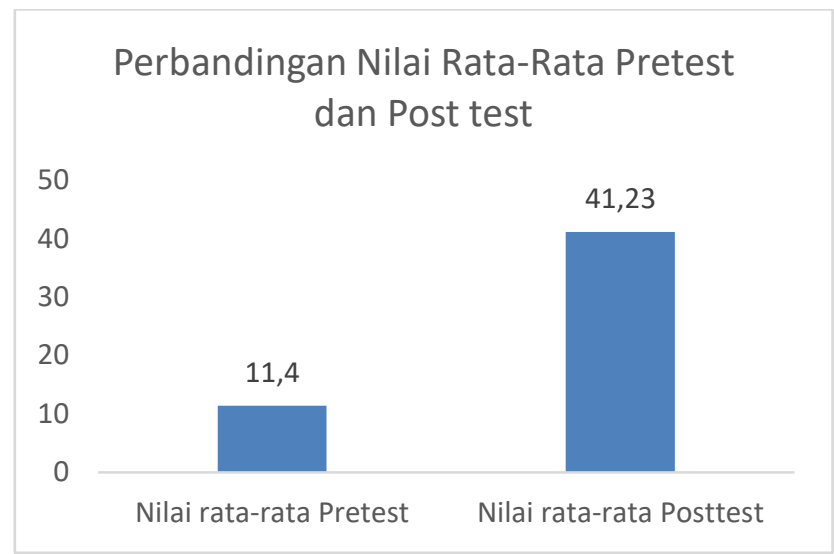

Gambar 3. Perbandingan Nilai Pre-test dan Post-test

Manfaat kegiatan untuk mitra yaitu bertambahnya wawasan manfaat olahraga serta aktivitas fisik yang baik dalam kehidupan sehari-hari. Edukasi kesehatan tentang pentingnya olah raga serta aktivitas yang baik adalah promosi kesehatan yang dilakukan adalah dengan metode penyuluhan untuk penambahan wawasan terkait aktivitas fisik, manfaat olah raga, tips olahraga yang benar serta aktivitas fisik yang dianjurkan untuk pengendalian tekanan darah. Edukasi kesehatan terkait olahraga bertujuan menambah pengetahuan serta wawasan mengenai aktivitas fisik, olahraga dan pentingnya penanganan dan pengendalian tekanan darah melalui kegiatan olahraga serta informasi yang didapat disampaikan kepada keluarga serta masyarakat di sekitarnya.

\section{KESIMPULAN}

Pelaksanaan kegiatan pengabdian "Kelola Tekanan Darah Melalui Aktivitas Fisik" berjalan dengan lancar dan peserta mengikuti rangkaian acara hingga selesai. Masih minimnya pengetahuan peserta terkait aktivitas fisik dan olahraga dapat dilihat berdasarkan nilai rata-rata pre test adalah 11,40 dan setelah penyampaian materi terjadi peningkatan pengetahuan dapat dilihat hasil pos test sebesar 41,23. Kegiatan ini dapat dilakukan kembali sebagai follow up dari hasil kegiatan pengabdian ini serta bekerjasama dengan kader untuk membina warganya untuk rajin berolahraga. Warga juga mengharapkan agar kegiatan in dapat dilakukan secara tatap muka.

\section{Ucapan Terima Kasih (Acknowledgement)}

Tim PKM mengucapkan terima kasih kepada Rektor Universitas Tarumanagara beserta jajaran, Lembaga Penelitian dan Pengabdian Masyarakat Univeristas Tarumanagara atas pendanaan sehingga kegiatan pengabdian. Tim juga mengucapkan terima kasih kepada Pimpinan Fakultas Kedokteran Universitas Tarumanagara beserta jajaran atas dukungannya dalam pelaksanaan kegiatan PKM. Terima kasih kepada peserta PKM atas dukungan dan partisipasinya dalam kegiatan ini dan Panitia SENAPENMAS atas kesempatan untuk berpatisipasi pada kegiatan SENAPENMAS 2021.

\section{REFERENSI}

Aubertin-Leheudre, M. and Rolland, Y. (2020). The Importance of Physical Activity to Care for Frail Older Adults During the Covid-19 Pandemic. Journal of the American Medical Directors Association. AMDA - The Society for Post-Acute and Long-Term Care Medicine, 21(7):973-976. doi: 10.1016/j.jamda.2020.04.022.

Hammami, A. et al. (2020). Physical activity and coronavirus disease 2019 (Covid-19): specific 
recommendations for home-based physical training. Managing Sport and Leisure, 0(0):16. doi: 10.1080/23750472.2020.1757494.

Halabchi, F., Ahmadinejad, Z. and Selk-Ghaffari, M. (2020) 'Covid-19 epidemic: Exercise or not to exercise; that is the question!', Asian Journal of Sports Medicine, 11(1):17- 19. doi: 10.5812/asjsm.102630.

Hongkong department of health. (2012) Exercise Prescription Doctor's handbook. Hongkong:

Kemenkes. 2020. Aktivitas Fisik di Masa Pandemi COVID-19 Bagi Orang dengan Faktor Risiko PTM. http://www.p2ptm.kemkes.go.id/kegiatan-p2ptm/dki-jakarta/aktivitas-fisik- di-masapandemi-covid-19-bagi-orang-dengan-faktor-risiko-ptm-2

Koch, S, Litt, J., Daher, C. \& Nieuwenhujisen, M. (2020). Should We The Coronavirus Activity During Allow Physical Disease Pandemic?. IS Global, pp. 1-5. https://www.isglobal.org/documents/10179/7943094/4_ISGlobal+COVID19+y+actividad+fisica+EN.pdf/705ac058-6c41-4e56-b555-cc43c6a5a407

Lukito AA, Harmeiwaty E, Hustrini NM.(2019)..Konsensus penatalaksanaan hipertensi 2019.

Jakarta: Perhimpunan Dokter Hipertensi Indonesia; 2019. http://faber.inash.or.id/upload/pdf/article_Update_konsensus_201939.pdf

WHO.(2015) | Prevalence of insufficient physical activity. diunduh dari : http://www.who.int/gho/ncd/risk_factors/physical_activity_text/en/

World Health Organization. (2009). Global health risks: mortality and burden of disease attributable to selected major risks. Geneva: World Health Organization;2009. https://www.who.int/healthinfo/global_burden_disease/GlobalHealthRisks_report_full.pdf

Roux L, Pratt M, Tengs TO, Yore MM, Yanagawa TL, Van Den Bos J, et al. (2008). Cost effectiveness of community-based physical activity interventions. Am J Prev Med 35(6):578-88

https://www.researchgate.net/publication/23465349_Cost_Effectiveness_of_CommunityBased_Physical_Activity_Interventions 